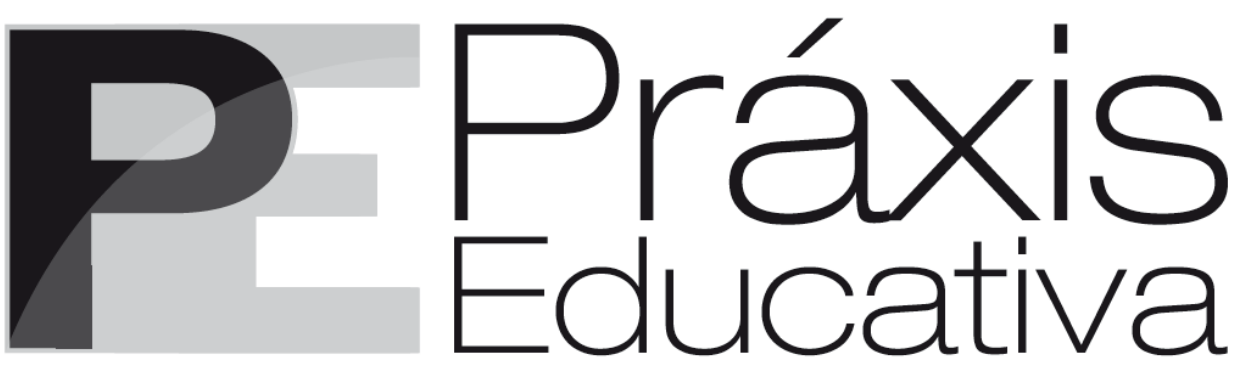

ISSN 1809-4309 (Versão online) DOI: 10.5212/PraxEduc.v.12i2.0007

\title{
Concepções de professores de Educação Física sobre inclusão escolar ${ }^{*}$
}

\section{Physical Education Teachers' conceptions of school inclusion}

\section{Concepciones de profesores de Educación Física sobre la inclusión escolar}

\author{
Raíssa Forte Pires Cunha* \\ Adriana Leite Limaverde Gomes ${ }^{* *}$
}

Resumo: O artigo analisa as concepções de inclusão que caracterizam os discursos de professores de Educação Física que acolhem estudantes com deficiência sensorial, física e/ou intelectual. A metodologia, de natureza qualitativa, caracterizou-se como um estudo de caso. Participaram deste estudo dois professores de Educação Física da rede regular de ensino pública da cidade de Fortaleza. Os procedimentos de coletas de dados consistiram na aplicação de entrevistas com base em um roteiro elaborado para esse propósito. Os resultados deste estudo evidenciaram que há um descompasso entre o discurso dos professores acerca da inclusão escolar: ora eles defendem uma concepção inclusiva e, em outros momentos, defendem concepções segregacionistas e exclusivistas para pessoas com deficiência. Conclui-se, com base nos discursos dos sujeitos participantes desta pesquisa, que suas concepções acerca da inclusão escolar ainda estão em vias de consolidação.

Palavras-chave: Inclusão. Educação Física. Concepções.

\begin{abstract}
This paper analyzes the conceptions of inclusion that characterize the discourses of physical education teachers who have students with sensory, physical or intellectual disabilities. The methodology was qualitative and developed a case study. Two physical education teachers from the education public system in the city of Fortaleza took part in this study. The data collection procedures included interviews based on a script previously elaborated for this purpose. The results evidenced that there is a gap between the teachers' discourses regarding school inclusion: since they sometimes defend an inclusive conception and other times advocate segregationist and exclusivist conceptions for people with disabilities. Based on the discourses of the participants of this study, it was concluded that their conceptions of school inclusion are still on the way to become consolidated.
\end{abstract}

Keywords: Inclusion. Physical Education. Conceptions.

Resumen: El artículo analiza las concepciones de inclusión que caracterizan los discursos de profesores de Educación Física que acogen estudiantes con discapacidad sensorial, física y/o intelectual. La metodología de carácter cualitativo, se calificó como un estudio de caso. El estudio incluyó dos profesores

\footnotetext{
* Financiamento: CAPES - Coordenação de Aperfeiçoamento de Pessoal de Nível Superior.

** Graduada em Educação Física e Mestre em Educação da Universidade Federal do Ceará (UFC). E-mail: $<$ raissafpcunha@gmail.com>.

*** Doutora em Educação da Universidade Federal do Ceará (UFC). E-mail: <adrianalimaverde@ufc.br>.
}

Práxis Educativa, Ponta Grossa, v. 12, n. 2, p. 414-429, maio/ago. 2017 Disponível em: <http://www.revistas2.uepg.br/index.php/praxiseducativa $>$ 
de educación física de la red regular de las escuelas públicas en la ciudad de Fortaleza. Los procedimientos de recolección de datos consistieron en aplicar entrevistas a partir de un guión elaborado para este propósito. Los resultados de este estudio mostraron que hay una falta de correspondencia entre el discurso de los profesores sobre la inclusión escolar: algunos abogan por un diseño inclusivo y, en otras ocasiones, defienden segregaciones y concepciones de exclusión para las personas con discapacidad. De acuerdo con las intervenciones de los participantes en este estudio se concluye que sus puntos de vista sobre la inclusión escolar se encuentran todavía en proceso de consolidación.

Palabras clave: Inclusión. Educación Física. Concepciones.

\section{Introdução}

O presente texto decorre de uma pesquisa de mestrado ${ }^{1}$ que fez uso de uma abordagem qualitativa para investigar as concepções de dois professores de Educação Física da rede pública de ensino de Fortaleza acerca da inclusão escolar de alunos público alvo da educação especial. O caminho pelo qual as pessoas com deficiência passaram até serem incorporadas na estrutura escolar comum foi marcado por trajetórias que vão desde a exclusão escolar, passando pela integração escolar até a inclusão escolar.

No âmbito escolar, o debate em torno da inclusão de pessoas com deficiência nas escolas comuns tem se ampliado nos últimos anos devido às mudanças advindas do documento da política educacional em 2008, que culminou com o advento da Escola Inclusiva (BRASIL, 2008). Esta política reestrutura a educação pública, garantindo o direito à educação de todas as crianças no ensino público regular. Dessa forma, tem aumentado significativamente a quantidade de matrículas de alunos com deficiência no ensino público do Brasil. Segundo Brasil (2014), o comportamento das matrículas em Educação Especial no período 2000-2013 revela um crescimento no atendimento dos alunos em escolas regulares e classes comuns de 695,2\%, enquanto o atendimento de escolas e classes especializadas decresceu 35,3\% no mesmo período.

Diante da nova realidade política da educação, as escolas se encontram em uma situação de reestruturação, a fim de ofertar um ensino de qualidade para alunos com e sem deficiência, que pressupõe mudanças significativas de conceitos e quebra de paradigmas, assim como mudanças estruturais dos espaços e a adoção de novas estratégias pedagógicas para atender as diferentes formas de aprender.

Acolher todas as pessoas, sem exceção, no meio escolar significa, a princípio, não excluir o aluno com deficiência do processo educacional (RODRIGUES, 2006). Mas, além disso, a presença do aluno no meio escolar não garante sua inclusão, como afirmam Mantoan (2006), Figueiredo (2010), e Ropoli et al. (2010), pois é necessário que o aluno com deficiência participe ativamente de todo o processo educacional. A inclusão escolar pressupõe garantir que o aluno com deficiência participe, com foco em suas potencialidades, de todas as atividades escolares e também que interaja com os outros alunos e os professores da escola.

Assim, inferimos que a perspectiva da educação inclusiva concebe a escola como um espaço de todos, no qual todos os alunos participam ativamente das tarefas de ensino e, para a

\footnotetext{
1 Pesquisa de mestrado intitulada "Educação Física escolar: concepções e princípios sobre inclusão escolar de professores da rede municipal de Fortaleza", defendida no Programa de Pós-graduação em Educação da Universidade Federal do Ceará, sob a orientação da professora Doutora Adriana Leite Limaverde Gomes. O estudo foi aprovado pelo Comitê de Ética da Universidade Federal do Ceará, cujo Certificado de Apresentação para Apreciação Ética é de número 44317215.0.0000.5054.
}

Práxis Educativa, Ponta Grossa, v. 12, n. 2, p. 414-429, maio/ago. 2017 Disponível em: <http://www.revistas2.uepg.br/index.php/praxiseducativa > 
inclusão efetiva do aluno com deficiência na escola, é necessário haver mudanças significativas das práticas pedagógicas dos professores, na forma de estruturação das aulas, da turma, dos materiais e dos recursos, por exemplo. Nesse processo de modificações na política e nos projetos pedagógicos das escolas, os professores também devem repensar e modificar suas práticas pedagógicas para garantir a participação de todos os alunos.

No âmbito da Educação Física escolar, assim como em outras disciplinas, a inclusão não acontece simplesmente porque o aluno com deficiência se encontra na quadra junto dos demais alunos sem deficiência. $\mathrm{Na}$ Educação Física, um importante passo para a efetivação da escola inclusiva consiste no desenvolvimento de atividades físicas das quais todos os alunos participem, para isso, essas atividades precisam, necessariamente, ser acessíveis.

Para Block (1994a, 1994b), a inclusão nas aulas de Educação Física acontece quando todos os alunos estão realizando a atividade em conjunto, com conteúdo previamente planejado pelos professores e com diferentes suportes, tais como estagiários e materiais adequados. Para Freitas e Leucas (2009), pensar a inclusão de alunos com deficiência nas aulas de Educação Física significa considerar um processo de ensino e aprendizagem que busque dar as mesmas oportunidades de vivência e de experiência a todos os alunos.

No contexto das relações humanas, Souza e Pich (2013) compreendem que a inclusão na Educação Física deve ter o significado de educar para a diferença, para a convivência e para a aceitação das diferentes configurações possíveis da corporeidade humana. Sassaki (1997) afirma que a Educação Física, no sentido da inclusão, deve promover uma educação com o objetivo de integrar a pessoa com deficiência no meio social por meio dessa área do conhecimento. Para Venturini et al. (2010), a área contribui para o desenvolvimento do afetivo, social e intelectual de alunos com deficiência, pois o incentivo à inclusão torna a autoestima e a autoconfiança mais evidente, contribuindo com a diminuição da desigualdade. Mauerberg de Castro e Castro (2011) afirma que a realização de atividades físicas por pessoas com deficiência contribui para a melhoria na realização das atividades de vida diária.

Diante do exposto, torna-se inquestionável a importância da prática de Educação Física por pessoas com deficiência e, quando se trata da Educação Física escolar é imprescindível que as aulas propiciem um ambiente de interação e cooperação entre os alunos, assim como o respeito às diferenças.

Entretanto, reconhecemos que realizar a inclusão de pessoas com deficiência na escola ainda é tarefa desafiadora para os profissionais da Educação Física. Souza e Pich (2013) afirmam que a prática pedagógica da Educação Física pouco tem superado a organicidade escolar segmentalizada, a fim de estabelecer uma prática verdadeiramente inclusiva.

Para que ocorra de fato uma prática de Educação Física inclusiva, é necessário que os professores, no contexto escolar de suas práticas, compreendam e articulem conceitos complexos que fundamentam a inclusão escolar, tais como: diferença, diversidade e identidade. Entretanto, segundo Carmo (2006), a Educação Física, na condição de conteúdo obrigatório nos níveis de ensino fundamental e médio, ainda tem utilizado como conhecimentos, em suas práticas, atividades físicas voltadas para classes homogêneas no tocante à idade, sexo, habilidades e capacidades físicas. O mesmo autor ainda enfatiza que a dúvida sobre saber o que fazer durante as aulas com os alunos com deficiência como cardiopatas, obesos ou pouco habilidosos tem rondado as práticas escolares brasileiras, inclusive na disciplina de Educação Física. Complementando esta ideia, Gorgatti et al. (2004) ressaltam que talvez, por confundir deficiência com doença, talvez por comodismo ou total falta de informação, o fato é que muitos professores

Práxis Educativa, Ponta Grossa, v. 12, n. 2, p. 414-429, maio/ago. 2017 Disponível em: <http://www.revistas2.uepg.br/index.php/praxiseducativa > 
privam seus alunos da oportunidade de vivenciarem experiências motoras e recreativas escolares, o que fatalmente trará conseqüências, por vezes, irreparáveis.

Entre as principais dificuldades relatadas pelos professores está a falta de conhecimento referente à inclusão de alunos com deficiência nas aulas de Educação Física, o que parece justificar a alegação dos mesmos quanto à falta de preparação para incluir, em suas aulas teóricas e práticas de Educação Física, alunos com deficiência (CHICON, 2011; CARMO, 2006; AGUIAR; DUARTE, 2005; GORGATTI et al., 2004; MAUERBERG DE CASTRO; CASTRO, 2011).

Essa realidade nos preocupa, visto que as mudanças nas concepções de deficiência, assim como na política educacional, apontam para um caminho no qual as pessoas com deficiência estão afirmando seus direitos. Conforme a OMS (2011), torna-se essencial conviver em um ambiente plural, em que pessoas sem deficiência tenham contato com aquelas com deficiência e assim haja redução do preconceito em relação às pessoas com deficiência.

Tendo em vista a importância da educação para a legitimação dos direitos das pessoas com deficiência na sociedade, faz-se necessário identificar em que passo os professores se encontram na internalização das concepções sobre inclusão escolar, inclusive os de Educação Física.

Com base nas considerações apresentadas, pretendemos neste texto identificar e analisar as concepções de educação inclusiva de professores de Educação Física que acolhem estudantes com deficiência sensorial, física e/ou intelectual em suas aulas.

\section{Método}

\section{Tipo de pesquisa}

Esta pesquisa se configura como uma pesquisa qualitativa e um estudo de caso, cujo objeto analisou um aspecto particular da inclusão escolar relativo às aulas de Educação Física referente às concepções de professores acerca da educação escolar inclusiva.

\section{Sujeitos}

Participaram deste estudo dois professores ${ }^{2}$ de uma escola pública de Fortaleza, pertencente ao sistema municipal de ensino. Eles foram selecionados com base nos seguintes critérios: professores de Educação Física do Ensino Fundamental que possuíam em suas turmas alunos com deficiência sensorial, física e/ou intelectual; professores que já atuavam como educador físico escolar há, pelo menos, um ano; professores que concordavam em participar da pesquisa.

Os dois professores sujeitos desta pesquisa são graduados em Educação Física e são identificados como EF1 e EF2. O EF1, do sexo masculino, possui especialização em Personal Trainner e atua na área escolar há 5 anos. No momento da pesquisa, em duas de suas turmas havia três alunos com deficiência. Na primeira turma, dois com deficiência intelectual e, na outra, um aluno com deficiência intelectual e dificuldades motoras. Enquanto o EF2 do sexo feminino, diferente de EF1, fez um curso de capacitação em Atividade Física Adaptada na Universidade de Juiz de Fora e atua na área há 23 anos. Na ocasião da pesquisa, em duas turmas de EF2 havia

${ }^{2}$ Os professores serão identificados respectivamente como EF1 e EF2.

Práxis Educativa, Ponta Grossa, v. 12, n. 2, p. 414-429, maio/ago. 2017 Disponível em: < http://www.revistas2.uepg.br/index.php/praxiseducativa> 
dois alunos com deficiência. Na primeira turma, um aluno com deficiência intelectual e, na outra, um aluno com deficiência auditiva.

\section{Instrumentos}

Para a coleta dos dados da presente pesquisa, utilizamos entrevistas com o objetivo de identificar as concepções dos sujeitos participantes ${ }^{3}$ em relação à inclusão escolar. Elas foram realizadas com base em um roteiro composto de 13 questões subjetivas que denominamos de Concepções e Princípios sobre Educação Física Inclusiva (Quadro 1). A utilização do roteiro teve o propósito de identificar qual era o entendimento dos professores de Educação Física sobre inclusão escolar, o que eles compreendiam do ensino da Educação Física na perspectiva inclusiva e, por fim, como os professores participantes deste estudo organizavam suas aulas a partir da presença de alunos com deficiência. No Quadro 1, abaixo, encontram-se as questões que foram usadas para este estudo.

Quadro 1 - Roteiro de entrevista "Concepções e Princípios sobre Educação Física Inclusiva”"

O que você entende sobre inclusão escolar?

Como se dá a Educação Inclusiva no contexto da Educação Física?

Você considera suas aulas inclusivas?

De que modo você costuma realizar as intervenções junto ao aluno com deficiência durante a realização das atividades de educação física?

Em sua opinião, em que ambiente as crianças com deficiência desenvolvem melhor suas capacidades escolares: em aulas de Educação Física do ensino regular ou em aulas na Escola Especial?

Em sua opinião, estudantes com deficiência nas aulas de Educação Física, podem ser melhor atendidos em turmas específicas, que trabalhem apenas com a Educação Física Adaptada e o Esporte Adaptado? Por quê?

Você acredita que o aluno com deficiência incluído no ensino regular que não participa das aulas de Educação Física é prejudicado em seu desenvolvimento motor, social, cognitivo e emocional?

Em função das características da criança com deficiência, ela pode ou não se desenvolver de maneira condizente nas aulas de Educação Física quando incluídas em turmas regulares? De que forma?

Você acredita que a atenção extra requerida pelos estudantes que apresentam deficiência pode prejudicar a fluidez das aulas de Educação Física e o desenvolvimento dos demais alunos?

Fonte: Elaborado pelas autoras.

${ }^{3}$ No presente texto focaremos apenas os dados relativos às concepções dos professores sobre inclusão escolar.

Práxis Educativa, Ponta Grossa, v. 12, n. 2, p. 414-429, maio/ago. 2017 Disponível em: <http://www.revistas2.uepg.br/index.php/praxiseducativa > 


\section{Procedimentos para a coleta de dados}

As entrevistas foram realizadas na própria escola dos professores participantes desta pesquisa, após terem lido e assinado o Termo de Consentimento Livre e Esclarecido. As entrevistas ocorreram de forma individual e com uma duração média de 30 minutos, no período do mês de novembro de 2014. Para o registro das entrevistas utilizamos a gravação direta em áudio, mediante a autorização dos sujeitos e, posteriormente, transcrevemos para a análise dos dados.

\section{Análise dos dados}

No presente estudo, optamos por utilizar o método de categorização para análise dos dados. Segundo Flick (2009), essa maneira de analisar os dados é mais destacada quando os dados resultam de entrevistas, observações e grupos focais. As principais atividades da categorização consistem em "buscar partes relevantes dos dados e analisá-los, comparando com outros dados e lhes dando nomes e classificações" (FLICK, 2009, p. 132).

Nosso percurso consistiu, a princípio, em realizar uma análise minuciosa das falas dos entrevistados com o objetivo de categorizar as informações que melhor respondiam aos objetivos deste trabalho.

\section{Resultados e discussão}

As recentes mudanças na escolarização de pessoas com deficiência, com o foco na inclusão, sinalizam a adoção de um método mais humanista de ensino, no qual o aluno deve ser o centro do processo de aprendizagem. Trata-se de um processo de mudança gradativo e sujeito a erros e acertos que podem pôr em dúvida o conhecimento do professor sobre como ensinar, como fazer, como propor e até como se comunicar, pois os professores se encontram em constante reconstrução de seus saberes docentes frente a inúmeros desafios.

Esse processo de mudanças e desafios no ensino é uma realidade para todos e também foi detectada nos discursos dos professores de Educação Física desta pesquisa. Ao analisarmos os dados obtidos nas entrevistas, percebemos que, por vezes, os professores se contradiziam no interior de seus próprios discursos. Ora expressavam opiniões favoráveis à inclusão e, em outros momentos, apresentavam um discurso a favor da integração escolar e, até mesmo, defendiam a segregação escolar de crianças com deficiência.

Com base nos resultados, analisaremos os dados das entrevistas a partir da classificação de três concepções acerca da inclusão escolar, são elas: concepção inclusiva, concep̧̧ão integracionista, concep̧̧ão exclusivista/segregacionista. Salientamos que a separação dessas concepções apresentadas pelos professores foi realizada para efeito didático na apresentação dos dados. Assim, nem sempre foi possível tratarmos desses dados de modo isolado, mas intencionamos favorecer o reconhecimento dessas concepções no decorrer da apresentação dos dados obtidos.

\section{Concepção Inclusiva}

Para ilustrar as concepções inclusivas dos professores, destacamos algumas falas dos participantes. Quando questionados sobre o conceito de inclusão, os dois professores participantes desta investigação manifestaram as seguintes concepções: 
EF1: "Acredito que inclusão é todo ato que você faz com que o aluno possa participar de qualquer processo, de qualquer [...] fato que gere o ensino para aquela criança, seja na parte de conteúdo cognitivo, seja motor, seja afetivo, seja social, mas desde que ela se sinta incluída dentro daquele processo que tá acontecendo".

EF2: "Inclusão, de maneira geral, é fazer com que o aluno participe do processo pedagógico, seja ele em sala, fora dela, no ambiente escolar".

Nos extratos dessas falas averiguamos que, para esses professores, incluir corresponde à participação de todos os alunos com deficiência no processo pedagógico em qualquer espaço escolar. A concepção de inclusão vinculada à participação de todos, de modo indistinto, corrobora os estudos de Figueiredo (2010), Mantoan (2003), Mattos et al. (2012), Rodrigues (2006), Ropoli et al. (2010) que afirmam que educar na perspectiva inclusiva implica na promoção de acessibilidade, no intuito de propiciar a participação de todos. Para esses autores, a escola deve ser um espaço de todos, independentemente de os alunos apresentarem ou não deficiência de qualquer natureza.

Sabemos que a presença do aluno com deficiência nas aulas de Educação Física não significa a garantia de sua participação ativa das propostas pedagógicas oferecidas nesse espaço de aprendizagem. Uma das dificuldades encontradas no processo de inclusão é criar um ambiente favorável à participação de todos os alunos, de modo que assegure a permanência de alunos com deficiência no ensino comum (MANTOAN, 2003). Para que a participação e a permanência do aluno com deficiência sejam garantidas é preciso avançar no atendimento a esse aluno de modo qualitativo.

Mantoan (2003) considera que a escola inclusiva é uma proposta real e possível, mas sua efetivação exigirá uma reorganização do trabalho escolar. A autora acrescenta ainda que a construção de uma escola inclusiva implica na ressignificação das práticas cotidianas de todos os que trabalham na escola, no sentido de garantir a participação e o respeito à singularidade dos sujeitos que se encontram nesse espaço educativo.

Retomando aos dados da pesquisa, questionamos os professores se eles consideravam que suas aulas de Educação Física promoviam a inclusão dos alunos que apresentavam deficiência. A seguir trechos de suas respostas:

$$
\begin{aligned}
& \text { EF1: "Acredito que na grande maioria das vezes sim [...] porque os alunos normalmente, na maioria } \\
& \text { das vezes, eles participam. Não têm uma recusa para participar [...]" } \\
& \text { EF2: "Nem todas [...] mas eu tenho sempre essa preocupação de fazer a aula de maneira que eles } \\
& \text { possam participar". }
\end{aligned}
$$

Consoante às falas em destaque, para esses professores, a maioria de suas aulas promovia a participação de todos os alunos. Compreendemos que a presença do aluno com deficiência em uma aula não significa a garantia de sua participação. A participação pressupõe mais do que a presença do aluno, visto que implica no engajamento do mesmo na atividade, de modo interativo com seus pares. Para que o aluno que apresenta deficiência se envolva na atividade, é necessário que ele sinta-se pertencente ao grupo e se vincule com a possibilidade de executar uma atividade física e de contribuir com seu grupo em uma situação lúdica de jogo ou de brincadeira.

Corroboramos a crença de que a prática pedagógica do professor de Educação Física, como o termo evidencia, constrói-se na prática, no contato com o outro, no diálogo com o aluno. Assim, a aquisição do conhecimento pelo professor para a realização de uma prática pedagógica inclusiva não ocorre de forma passiva, mas de modo ativo. Nesse contexto, o professor empenha-se em buscar conhecimentos porque constatou, na prática, que era necessário. 
Compreendemos que o conhecimento origina-se além dos cursos de capacitação e de formação. Ele pode ser adquirido por meio da experiência com o próprio aluno com deficiência, das informações colhidas do aluno com base no diálogo com a família dele, assim como de encontros científicos, de livros, e do compartilhar de experiência com outro professor.

A concepção inclusiva de EF1 e EF2 se revelou em seus discursos, na medida em que ambos demonstravam preocupação em proporcionar a participação dos alunos com deficiência em suas aulas. EF1 afirma que não há recusa dos alunos com deficiência para se engajar nas atividades. Já EF2 defende que o desenvolvimento das aulas deve favorecer a participação de todos os alunos. Desse modo, infere-se, por meio das falas dos dois professores, que incluir implica, necessariamente, promover a participação de todos os alunos.

\section{Concepção integracionista}

Reconhecemos também a concepção integracionista dos professores participantes deste estudo nos dados obtidos das entrevistas. Verificamos que, se na concepção inclusiva os professores defendiam a inclusão como participação de todos os alunos, na concepção integracionista, eles alertavam que para incluir é necessário levar em consideração as limitações dos alunos. A presença da concepção integracionista pode ser percebida nos trechos de falas a seguir:

EF1: "Na Educação Física a gente procura trabalhar [...] levando sempre em consideração a deficiência que ele tem e de que forma, dentro daquela atividade, ele vai poder participar [...]”.

EF2: "[...] eles participam [refere-se aos alunos com deficiência] da aula normalmente, como os outros alunos, obedecendo às limitaçôes de cada um. Então dentro do que eles podem fazer, dentro das limitações deles, eles podem participar das atividades".

Nesses trechos, ao passo que EF1 e EF2 reafirmaram que a inclusão correspondia à participação dos alunos com deficiência no processo de ensino, eles defendiam que, para que essa participação ocorra, deve-se levar em conta as limitações desses alunos. A ênfase nas limitações sugere o estacionamento das habilidades e capacidades dos alunos e determina o que eles podem fazer ou se eles podem ou não participar de uma determinada atividade. Essa compreensão integracionista se contrapõe à concepção inclusiva defendida por estudiosos da área (BLOCK, 1994a; 1994b; MANTOAN, 2003; ROPOLI et al., 2010), que sinalizam que para incluir não se deve condicionar a participação do aluno, sob o pretexto de sua deficiência.

Segundo a OMS (2011), enfatizar grupos de habilidades é muitas vezes um grande desafio para a inclusão. Para a organização de um contexto inclusivo, o caminho a ser seguido é a adoção de abordagens mais centradas nas potencialidades do aluno e não em sua deficiência.

Portanto, garantir a participação do aluno levando em consideração suas limitações, não condiz com uma participação plena e não caracteriza também, um processo de ensino inclusivo. Estudos feitos por Mantoan (2003) e Ropoli et al. (2010) asseveram que a proposta da educação na perspectiva da inclusão escolar é a criação de uma escola para todos, sem discriminação e sem opções de se trabalhar à parte com alguns alunos. Ou seja, nessa perspectiva, não existe uma aula específica para o aluno com deficiência e outra aula destinada ao aluno sem deficiência. A aula deve ser planejada e desenvolvida tendo em vista que todos os alunos aprendam juntos, em interação, porque acreditamos ser isto importante para o desenvolvimento corporal e para a aprendizagem de todos. 
Planejar e executar as atividades físicas tendo em vista as limitações dos alunos com deficiência, ponto de vista defendido por EF1 e EF2, implica em delimitar o que os alunos podem ou não fazer. A proposta da educação na perspectiva da inclusão pressupõe um trabalho com as diferenças existentes entre os alunos, e não a adoção de uma diferenciação de ensino entre eles. Esta última perspectiva de educação se afina com a concepção integracionista.

Em outro momento da entrevista, questionamos EF2 se concordava que os estudantes com deficiência teriam um melhor atendimento em turmas específicas de Educação Física, que trabalhassem com o esporte adaptado. E, em sua resposta, EF2 demonstrou ser favorável às turmas específicas, conforme podemos destacar em sua fala:

\begin{abstract}
EF2: "Em alguns aspectos sim. Porque a gente... a dinâmica que a gente... da nossa aula é muito grande. Então às vezeses ele [se refere ao aluno com deficiência] tá precisando de uma atenção maior, ou de uma atividade, até um ponco mais diferenciada, ou com um grau menor de dificuldade, e a gente não pode é se limitar a ele... [...] não posso fazer um trabalho especifico para ele. Tenho que fazer um trabalho globalizado e nas aulas específicas do esporte adaptado, ele tem maior condição, né? As vezes eu deixo um pouco de lado a criança com deficiência... ela fica um pouco, eu confesso que eu não consigo integrar cem por cento, do começo da aula até o final não".
\end{abstract}

No trecho destacado da fala de EF2, percebe-se que ele se mostra favorável à educação em turmas específicas de Educação Física, ao justificar que os alunos com deficiência, devido a sua condição, precisam de um trabalho diferenciado e este trabalho não pode ser ofertado nas turmas regulares. A visão de EF2 se assemelha ao conceito de integração na escola. Esta concepção surgiu como uma possibilidade de organizar ou manter pessoas com deficiência em classes regulares ou em classes especiais dentro das escolas regulares (BRASIL, 2008).

O professor EF2 mencionou que não podia fazer um trabalho diferenciado, com grau menor de dificuldade e com maior atenção para o aluno com deficiência na turma regular. $\mathrm{Na}$ perspectiva da inclusão escolar, compreendemos que o professor pode e deve promover atividades acessíveis a todos os alunos e, até mesmo adequar, se forem necessárias, algumas atividades visando à participação, ao desenvolvimento e à aprendizagem de todos os alunos.

A concepção integracionista fundamenta a fala de EF2, quando ele se referiu à presença do aluno, sob a condição de sua adaptação à turma. Nesse contexto, para EF2, o esforço deveria partir do aluno para se adaptar ao meio, e não o contrário, o meio se adequar às diferenças humanas.

O trecho da fala de EF2 "às vezes eu deixo um pouco de lado a criança com deficiência [...] ela fica um pouco, eu confesso que eu não consigo integrar cem por cento do começo da aula até o final não" demonstra sua intenção de categorizar os alunos segundo a maior ou menor habilidade motora para participar de uma atividade da aula de Educação Física. Para EF2, quando ele desenvolve uma atividade com maior grau de dificuldade, não é possível favorecer a participação de um aluno que apresente deficiência.

Em relação à proposta de atividades com menor grau de dificuldade, defendemos que uma mesma atividade física pode ser realizada por todos os alunos de uma turma. Para que haja acessibilidade, o professor de Educação Física deve adequar a atividade mediante o uso de recursos e materiais, considerando as potencialidades do aluno que apresenta deficiência. A promoção de acessibilidade às aulas de Educação Física implica na seleção de estratégias de ensino que podem envolver modificações de materiais (KASSER; LIEBERMAN, 2003; DUGAS; POINT, 2014), ou mudanças e adequações das atividades físicas (DUGAS; POINT, 2014; KASSER; LIEBERMAN, 2003; SILLA; GROSSO; WILLIAMS, 2009). Trata-se de mudanças que podem contribuir e favorecer a participação do aluno com deficiência.

Práxis Educativa, Ponta Grossa, v. 12, n. 2, p. 414-429, maio/ago. 2017 Disponível em: <http://www.revistas2.uepg.br/index.php/praxiseducativa $>$ 
Segundo Mauerberg de Castro e Castro (2011), as atividades não devem categorizar os seres humanos como aqueles com ou sem deficiência, mas deve-se analisar as diferenças individuais associadas aos problemas no domínio psicomotor e evitar que elas definam negativamente a identidade de aluno, de atleta e de pessoa.

No que se refere ao trabalho diferenciado, EF2 defende que "a criança com deficiência precisa de uma atividade mais diferenciada". Na literatura, autores como Ropoli et al. (2010), enfatizam que, na escola inclusiva, trabalhar na perspectiva das diferenças pressupõe romper com oposições binárias tais como: normal/especial; branco/negro; rico/pobre. Segundo os estudiosos, é importante ter em mente que não se deve diferenciar o aluno pela deficiência que ele apresenta ou por alguma outra característica que não é comum aos demais pares, pois a criança com deficiência é antes de tudo uma criança.

Retomando a fala de EF2 "Porque a gente... a dinâmica que a gente... da nossa aula é muito grande. Então às vezes ele [se refere ao aluno com deficiência] tá precisando de uma atenção maior, ou de uma atividade até um ponco mais diferenciada, ou com um grau menor de dificuldade e a gente não pode se limitar a ele", verificamos nesse trecho que para EF2 alguns alunos com deficiência requerem maior atenção. De fato, alguns alunos, devido as suas dificuldades de locomoção, podem demandar a necessidade de um profissional de apoio para auxiliar em seus deslocamentos pela escola, salientamos que a presença desse profissional não substitui o papel do professor de ensinar a turma toda. Segundo Mittler (2000), a educação inclusiva não é incompatível com a noção de apoio que "pode ser planejado e oferecido com um assistente de apoio à aprendizagem ou outro professor na sala de aula" (MITTLER, 2000, p. 35). O professor é sempre o responsável por sua turma, portanto, não deve delegar para outro profissional atribuições que lhes são próprias.

Podemos inferir, portanto, que a inclusão de crianças com deficiência no ensino comum requer esforço por parte dos professores e dos gestores, assim como um bom planejamento de aula. Destacamos que, na inclusão escolar, é a escola que tem que se adequar para receber os alunos e não o contrário.

$\mathrm{Na}$ fala do professor EF2, outro aspecto nos chamou atenção, quando ele demonstrou preocupação com a presença do aluno com deficiência, argumentando que esse aluno pudesse interferir na progressão de sua aula. Sobre este aspecto, os resultados da pesquisa de Block e Zeman (1996) sugerem que, com suporte apropriado, estudantes com deficiência severa podem ser incluídos em um programa de Educação Física escolar sem afetar negativamente os demais estudantes sem deficiência. A OMS (2011) também afirma que "a inclusão de alunos com deficiência não é geralmente considerada como tendo impacto negativo no desempenho de aluno sem deficiência" (p. 220).

Block (1994a), em outro estudo, de natureza comparativa entre turmas com e sem alunos com deficiência, verificou que não houve diferença significativa na aquisição de habilidades motoras entre os estudantes sem deficiência que participavam de aulas de Educação Física junto a estudantes com deficiência e a turma de alunos que possuía apenas alunos sem deficiência.

Com base nos resultados desses estudos, entendemos que a realização de uma atividade física na perspectiva da inclusão, ou seja, com a presença de pessoas com deficiência, quando bem orientada, com base em princípios inclusivos e com materiais e suportes adequados não limita, nem atrasa, tampouco prejudica o desenvolvimento dos demais alunos sem deficiência. Pelo contrário, ela pode beneficiar o desenvolvimento das habilidades e das capacidades motoras de todos os alunos, sejam eles com ou sem deficiência.

Práxis Educativa, Ponta Grossa, v. 12, n. 2, p. 414-429, maio/ago. 2017 Disponível em: <http://www.revistas2.uepg.br/index.php/praxiseducativa> 
Nesta investigação, verificamos que os discursos dos professores assinalam frágeis concepções, mas, por vezes, elas se aproximam da perspectiva inclusiva, apesar das contradições e compreensões que se vinculam com discursos integracionistas e até mesmo segregacionistas, como veremos a seguir.

\title{
Concepção exclusivista/segregacionista
}

Quando indagamos aos participantes qual o local de ensino mais indicado para os alunos com deficiência, eles responderam que, para algumas crianças, o melhor local de ensino seria uma instituição especializada, como podemos verificar nas falas destacadas:

\begin{abstract}
EF1: "[...] a escola especial... ela tem todo um aparato, profissionais formados e capacitados para trabalhar aquilo que o aluno necessita. [...] La ela vai conseguir ter um melhor desenvolvimento pelo fato de ter profissionais e estruturas [...] quanto mais qualidade, quanto mais capacidade, quanto mais estrutura, melhor os resultados vão acontecer".

EF2: "Eu não conbeço o trabalho da Escola Especial, mas acredito que ela seja melhor, que ela trabalha, assim, um pouco mais voltada para necessidade específica do aluno (...) e nas nossas aulas a gente não trabalha a necessidade específica do aluno! A gente trabalha de maneira coletiva. [pausa]... Claro que tem as particularidades, mas em termos de interação e socialização, com certeza a escola, ela proporciona um melhor ambiente".
\end{abstract}

Percebemos nessas falas que para EF1 e EF2, os profissionais mais capacitados para lidar com as crianças com deficiência são aqueles da escola especial, corroborando a concepção segregacionista e exclusivista de educação escolar. Estudo realizado por Falkenbach, Werle e Drexsler (2007) discute a problemática da prática da escola de educação especial. De acordo com esses pesquisadores, a educação especial isola cada vez mais a criança das experiências coletivas e das relações diferentes. Segundo os estudiosos, as escolas especializadas construíram um mundo a parte para as pessoas com deficiência e reafirmam que elas não devem conviver em conjunto com as pessoas sem deficiência.

A escola é local de ensino, de compartilhamento de ideias, de interação e de convivência entre os alunos. Quando se trata da disciplina de Educação Física escolar, ela tem como principal objetivo que seus alunos experimentem vivências corporais, tais como danças, lutas e esportes, pois o movimento, a atividade, a troca corporal são essenciais para o desenvolvimento humano. Enfatizamos isso para esclarecer que a escola não é local de reabilitação e terapia, mas sim local de ensino e aprendizado. Então, discordamos da necessidade de haver profissionais em turmas regulares para se trabalhar nessa ou naquela necessidade específica do aluno.

Acreditamos que defender a escola especial, significa ter um posicionamento favorável à segregação do ensino. Essa concepção confirma a exclusão social e marginaliza as pessoas com deficiências por causa de suas condições físicas

Retomando a fala de EF1, destacamos o trecho em que ele afirma que "[...] os profissionais das instituições especiais seriam mais capacitados para ensinar crianças com deficiência". Esse resultado corrobora os estudos de Miles (2009 apud OMS, 2011) que afirmam que na Zâmbia, professores de escolas básicas e primárias expressaram interesse na inclusão de crianças com deficiência, mas acreditavam que o trabalho seria reservado a especialistas.

Na literatura, os estudos de Mantoan (2003) evidenciam que a visão de que os professores mais preparados são aqueles que detêm o conhecimento especializado é uma percepção que denuncia a fragilidade dos professores da escola comum em realizar e conceber a inclusão escolar.

Práxis Educativa, Ponta Grossa, v. 12, n. 2, p. 414-429, maio/ago. 2017 Disponível em: <http://www.revistas2.uepg.br/index.php/praxiseducativa > 
Percebemos que os professores que reconhecem a Escola Especial como um local de melhor desenvolvimento do aluno se manifestam contra o princípio da educação inclusiva, que se respalda em um sistema escolar único. Ora, se a inclusão pressupõe que o aluno com deficiência se "sinta incluido dentro daquele processo" como enfatiza o professor EF1, quando questionado sobre o que é inclusão, como isso acontecerá com o aluno fora do processo? Como um aluno com deficiência se sentirá incluído em um sistema de ensino especial que é segregador, excludente e organizado, majoritariamente, por categorias de deficiência?

Quando indagamos os professores sobre qual seria a escola mais adequada para alunos com deficiência, EF2 afirmou que "em termos de interação e socialização com certeza a escola, ela proporciona um melhor ambiente". A partir disso, recorremos às contribuições de Vygotsky (2001), nas quais o autor preconiza que a interação é uma peça fundamental no processo de ensinoaprendizagem dos alunos, inclusive para aqueles que têm deficiência. Essa afirmação corrobora a importância de se ofertar um ensino comum a todos, visto que ele pode favorecer o desenvolvimento de crianças com e sem deficiência.

Entretanto, apesar de o professor EF2 afirmar que em termos de interação e socialização a escola regular proporciona um melhor ambiente para o desenvolvimento da criança com deficiência, há contradição em sua fala no momento em que defende o ensino na Escola Especial porque "ela trabalha, assim, um ponco mais voltada para necessidade específica do aluno". Desse modo, neste discurso, há uma concepção segregacionista de ensino, na medida em que EF2 compreende que os alunos com deficiência teriam um melhor atendimento em turmas específicas de Educação Física que trabalhem com o esporte adaptado.

Os pesquisadores Mittler (2000), Mantoan (2003) e Ropoli et al. (2010) destacam que na perspectiva da educação inclusiva suprime-se a divisão dos sistemas escolares em modalidades de ensino especial e regular. Ou seja, os estudiosos afirmam que incluir é não deixar nenhuma criança fora da escola regular, sobretudo aquelas que possuem deficiência, pois não existe inclusão em um sistema de ensino segregado.

Verificamos que os professores de Educação Física desta pesquisa apresentaram, em algumas falas, uma concepção de inclusão em que ainda se apregoa a divisão de duas modalidades de ensino; regular e especial e ainda a necessidade da presença de professores especialistas nesta ou naquela deficiência. Entretanto, é importante ter em vista que a educação inclusiva vai de encontro à seleção de alunos para o ensino, ela acolhe todos os alunos, independente de suas deficiências e dificuldades de aprendizagem.

É importante lembrar que o processo de inclusão escolar não exclui a capacitação de professores e mudanças estruturais e até políticas na escola. Aliás, consideramos ser ela essencial para o sucesso da inclusão escolar. A OMS (2011) enfatiza a eficácia da capacitação ao dar o exemplo de um programa de formação sobre educação inclusiva realizado na Mongólia para pais e professores com apoio de especialistas, em que 1.600 professores participantes demonstraram atitudes altamente positivas a favor da inclusão de crianças com deficiência. Inclusive, no país, a matrícula de crianças com deficiência em unidades de pré-escola aumentou de $22 \%$ para $44 \%$.

Mittler (2000) reafirma que, no campo da educação, a inclusão envolve um processo de reforma e de reestruturação das escolas em termos de currículo, avaliação, pedagogia e formas de agrupamentos dos alunos nas atividades de sala de aula e, principalmente, a formação e capacitação de professores.

Reconhecemos que, por ser a educação inclusiva uma política relativamente nova, é provável que os professores ainda estejam no processo de internalização do conhecimento e não

Práxis Educativa, Ponta Grossa, v. 12, n. 2, p. 414-429, maio/ago. 2017 Disponível em: <http://www.revistas2.uepg.br/index.php/praxiseducativa > 
nos surpreende o comum sentimento de insegurança que se reflete nos seus discursos e nas práticas pedagógicas. Nesse contexto, percebemos que os professores de Educação Física ainda estão reelaborando ou mesmo construindo seus saberes teóricos e práticos, considerando a nova realidade educacional. Assim, concordamos com Mantoan (2003), quando afirma que é importante que conteúdos referentes à inclusão estejam presentes desde a formação inicial até a formação continuada.

A ruptura com concepções integracionistas e segregacionistas implicará na construção de uma escola aberta às diferenças, que seja livre de preconceitos e acolhedora de todo e qualquer aluno, independente de suas limitações físicas, sensoriais, e/ou intelectuais. O acolhimento exigirá a promoção de práticas acessíveis, pautadas na diversidade de recursos e de materiais visando à participação de todos.

\section{Considerações finais}

No presente estudo, identificamos descompasso entre as falas dos professores de Educação Física sujeitos dessa pesquisa. Se por um lado eles demonstram sensibilidade em relação à inclusão escolar de alunos com deficiência, por outro lado sinalizam, por meio de discursos divergentes, que apregoam a exclusão dessa parcela da população.

Verificamos dualidade nos discursos dos sujeitos desta investigação, na medida em que eles revelaram concepções excludentes ao indicarem posição favorável ao ensino segregado em instituições especializadas.

As contradições no interior dos discursos dos professores sujeitos deste estudo sugerem que existe uma fragilidade em seus conhecimentos acerca da inclusão, segregação e exclusão. Esse resultado é compreensível diante da situação política educacional do país. A Política da Educação Especial na Perspectiva da Educação Inclusiva (2008) é recente, portanto é cabível considerar que os professores não tiveram oportunidades suficientes em suas formações, inicial e continuada, para discutir as concepções pautadas na valorização das diferenças de cada ser humano, que permeiam a inclusão.

Neste estudo, um dos professores realizou um curso na área de educação inclusiva, no entanto, o fato de participar de um curso não determina de imediato a mudança de suas concepções. Certamente, a experiência prática e a convivência com o aluno com deficiência contribuirão para a construção de uma concepção pautada na inclusão.

Em relação ao papel do professor no meio educacional, acreditamos que contribui com a inclusão escolar quando ele recebe o aluno com deficiência em suas aulas, quando ele reflete sobre como incluir e de que forma incluir, quando ele assume os receios, mas demonstra coragem para continuar tentando realizar uma aula para todos da melhor forma possível. Esses valores mencionados foram demonstrados pelos professores desta pesquisa e merecem ser valorizados.

A presença do aluno com deficiência na escola promove uma nova organização, assim como incentiva os professores à busca por formação, conhecimento e mudanças em suas práticas pedagógicas. Se o atendimento educacional fosse negado à pessoa com deficiência, provavelmente, questões como formação, inclusão, conhecimento, concepção sobre inclusão não estariam sendo debatidas com tanto fervor no meio educacional.

Há ainda muitos problemas a serem sanados em relação à educação inclusiva, portanto uma reflexão sobre isto é necessária. Diante deste contexto, é importante que a academia contribua com mais estudos que apresentem e discutam a realidade da Educação Física escolar na

Práxis Educativa, Ponta Grossa, v. 12, n. 2, p. 414-429, maio/ago. 2017 Disponível em: <http://www.revistas2.uepg.br/index.php/praxiseducativa > 
perspectiva da inclusão, como se configura a inclusão nas aulas de Educação Física das escolas do país e de que tipo de formação os professores estão participando na perspectiva inclusiva, a fim de traçar diretrizes, programas e incentivos para auxiliar os professores na tarefa de incluir todos os alunos.

\section{Referências}

AGUIAR, J. S.; DUARTE, E. Educação inclusiva: um estudo na área de educação física. Revista Brasileira de Educação Especial, Marília, v. 11, n. 2, p. 223-240, maio/ago. 2005. DOI: 10.1590/S1413-65382005000200005

BLOCK, M. E. Why all students with disabilities should be included in regular Physical Education. Palaestra, Macomb, v. 10, n. 3, p. 17-24, 1994a.

BLOCK, M. E. Disabilities should be included in regular physical education. Palaestra, Macomb, 1994b. Disponível em: < http://faculty.virginia.edu/ape/Articles/Block.Why-All-Students-WithDisabilities-Should-Be-Included-In-Regular-Physical-Education.pdf>. Acesso em: 21 abr. 2014.

BLOCK, M. E.; ZEMAN, R. Including students with disabilities in regular physical education: effects on nondisabled children. Adapted Physical Activity Quarterly, v. 13, p. 38-49, 1996.

BRASIL. Ministério da Educação. Secretaria de Educação Especial. Política Nacional de Educação Especial na Perspectiva da educação inclusiva. Inclusão Revista da Educação Especial, Brasília, v. 4, n. 1, jan./jun. 2008. Disponível em: <http://portal.mec.gov.br/arquivos/pdf/politicaeducespecial.pdf>. Acesso em: 21 abr. 2014.

BRASIL. MEC/SEESP. Relatório Educação para Todos no Brasil 2000-2015. Versão Preliminar. Junho de 2014.

CARMO, A. A. Atividade motora adaptada e inclusão escolar: caminhos que não se cruzam. In: RODRIGUES, D. (Org.). Atividade motora adaptada: alegria do corpo. São Paulo: Artes Médicas, 2006. p. 51-62.

CHICON, J. F. Inclusão na Educação Física escolar: considerações sobre a constituição da subjetividade humana. Movimento, Porto Alegre, v. 17, n. 1, p. 41-58, jan./mar. 2011.

DUGAS, C.; POINT, M. L'inclusion in éducation physique: notions théoriques et applications pédagogiques. Presses de l’Université du Québec: Québec, 2014.

FALKENBACH, A. P.; WERLE, V.; DREXSLER, G. A escola e a educação física diante da inclusão. Recife, 2007. Disponível em: <http://www.ceap.br/ material/MAT05022010151303.pdf>. Acesso em: 30 jun. 2014.

FIGUEIREDO, R. V. A escola de atenção as diferenças. In: FIGUEIREDO, R. V.; BONETI, L. W.; POULIN, J.-R. Novas Luzes sobre a Inclusão Escolar. Fortaleza: Edições UFC, 2010. p. 51-69.

FLICK, U. Introdução a pesquisa qualitativa. Tradução Joice Elias Costa. 3. ed. Porto Alegre: Artmed, 2009. 
FREITAS, A. F. S.; LEUCAS, C. B. O desafio da inclusão: o professor de educação física e a construção do processo de ensino e aprendizagem com a participação de um aluno com deficiência. In: CONGRESSO BRASILEIRO DE CIÊNCIAS DO ESPORTE, 16., CONGRESSO INTERNACIONAL DE CIÊNCIAS DO ESPORTE, 3., 2009, Salvador. Anais... Salvador, 2009.

GORGatTi, M. G.; PENTEADO, S. H. N. W; PINGE, M. D.; ROSE, D. Atitude dos professores de Educação Física do ensino regular em relação a alunos portadores de deficiência. Revista Brasileira de Ciência e Movimento, v. 12, n. 2, p. 63-68, 2004.

KASSER, S. L.; LIEBERMAN, L. J. Maximizing learning opportunities through activity modification. Kinesiology, Sport Studies and Physical Education Faculty Publications, NY, Paper 55, p. 19-22, May 2003.

MANTOAN, M. T. E. Inclusão escolar: O que é? Por quê? Como fazer? São Paulo: Moderna, 2003.

MANTOAN, M. T. E. Igualdade e diferenças na escola como andar no fio da navalha. Revista Educação, Santa Maria, v. 29, n. 1, p. 55-64, 2006.

MAUERBERG DE CASTRO, E.; CASTRO, R. M. Atividade física adaptada na escola inclusiva. In: MAUERBERG DE CASTRO, E. (Org.). Atividade física adaptada. 2. ed. Ribeirão Preto: Novo Conceito, 2011. p. 497-530.

MATTOS, I. S.; OLIVEIRA, E. A.; RIBEIRO, R. R. R. P. C.; SANTOS, G. C. S. Educação especial e inclusiva: conceitos, definições e o aluno com necessidades educacionais especiais. Fortaleza: UAB: UECE, 2012. Cap. 1.

MITTLER, P. Working towards inclusive education: social contexts. David Fulton Publishers. New York: David Fulton Publishers, 2000.

OMS. Relatório Mundial sobre a Deficiência/World report on disability. Tradução: Lexus Serviços Linguístico. São Paulo, 2011.

RODRIGUES, D. Dez idéias (mal) feitas sobre educação inclusiva. In: RODRIGUES, D. (Org.). Inclusão e Educação: doze olhares sobre a educação inclusiva. São Paulo: Summus, 2006. p. 299-318.

ROPOLI, E. A.; MANTOAN, M. T. E.; SANTOS, M. T. C. T.; MACHADO, R. A educação especial na perspectiva da inclusão escolar: a escola comum inclusiva. Fortaleza: UFC, 2010.

SASSAKI, R. K. Inclusão: construindo uma sociedade para todos. Rio de Janeiro: WVA 1997.

SILLA, V. A.; GROSSO, J.; WILLIAMS, D. Adapted physical education services, class wide peer tutoring and game modifications for health: physical education instruction. Health, Physical Education, Recreation \& Dance. PSAHPERD, University of Scranton, v. 79, n. 3, p. 27-32, 2009. 
SOUZA, G. C.; PICH, S. A reorientação da ação pedagógica na Educação Física sob a perspectiva da inclusão: a pesquisa-ação como caminho. Movimento, Porto Alegre, v. 19, n. 3, p. 149-169, jul./set. 2013.

VENTURINI, O. R. G.; RODRIGUES, M. B.; MATOS, G. D.; ZANELA, L. A.; JÚNIOR, P. L. R.; PAULA, R. R. G.; CUNHA, S. A.; FILHO, M. L. M. A importância da inclusão nas aulas de Educação Física escolar. Revista Digital, Buenos Aires, v. 15, n. 147, 2010.

VYGOTSKY, L. S. Psicologia pedagógica. São Paulo: Martins Fontes, 2001.

Recebido em 10/06/2016

Versão final corrigida recebida em 23/10/2016

Aceito em 04/11/2016 